\title{
Tailoring heated intraperitoneal mitomycin C for peritoneal metastases originating from colorectal carcinoma: a translational approach to improve survival
}

R Kwakman 1,6, E M V de Cuba 1,6, J P de Winter ${ }^{2,4}$, I H J T de Hingh ${ }^{3}$, P M Delis-van Diemen ${ }^{4}$, M Tijssen ${ }^{4}$, M A Rooimans ${ }^{2}$, O Krijgsman ${ }^{4}$, B Carvalho ${ }^{4}$, G J Peters ${ }^{5}$, H J Bonjer ${ }^{1}$, G A Meijer ${ }^{4}$ and E A te Velde ${ }^{\star}, 1$

1 Department of Surgical Oncology, Cancer Center Amsterdam and VU University Medical Center, De Boelelaan 1117, Amsterdam 1081 HV, The Netherlands; ${ }^{2}$ Department of Clinical Genetics, Cancer Center Amsterdam and VU University Medical Center, De Boelelaan 1117, Amsterdam 1081 HV, The Netherlands; ${ }^{3}$ Department of Surgery, Catharina Ziekenhuis Eindhoven, Eindhoven, The Netherlands; ${ }^{4}$ Department of Pathology and Tumour Profiling Unit, Cancer Center Amsterdam and VU University Medical Center, De Boelelaan 1117, Amsterdam 1081 HV, The Netherlands and ${ }^{5}$ Department of Oncology, Cancer Center Amsterdam and VU University Medical Center, De Boelelaan 1117, Amsterdam 1081 HV, The Netherlands

Background: Patients with peritoneal metastases (PMs) originating from colorectal carcinoma (CRC) are curatively treated by cytoreductive surgery (CRS) and hyperthermic intraperitoneal chemotherapy (HIPEC) with mitomycin C (MMC). We aim to improve patient selection for HIPEC by predicting MMC sensitivity.

Methods: The MMC sensitivity was determined for 12 CRC cell lines and correlated to mRNA expression of 37 genes related to the Fanconi anaemia (FA)-BRCA pathway, ATM-ATR pathway and enzymatic activation of MMC. Functionality of the FA-BRCA pathway in cell lines was assessed using a chromosomal breakage assay and western blot for key protein FANCD2. Bloom syndrome protein (BLM) was further analysed by staining for the corresponding protein with immunohistochemistry (IHC) on both CRC cell lines $(n=12)$ and patient material $(n=20)$.

Results: High sensitivity correlated with a low BLM $(P=0.01)$ and BRCA2 $(P=0.02)$ at mRNA expression level. However, FA-BRCA pathway functionality demonstrated no correlation to MMC sensitivity. In cell lines, weak intensity staining of BLM by IHC correlated to high sensitivity $(P=0.04)$ to MMC. Low BLM protein expression was significantly associated with an improved survival in patients after CRS and HIPEC $(P=0.04)$.

Conclusions: Low BLM levels are associated with high MMC sensitivity and an improved survival after HIPEC.

Mitomycin C (MMC) is used for hyperthermic intraperitoneal chemotherapy (HIPEC) that, combined with cytoreductive surgery (CRS), comprises the treatment of patients with peritoneal metastases (PMs) originating from colorectal carcinoma (CRC)
(Chua et al, 2012a). Because of the characteristics of PMs, CRS will leave microscopic disease in situ, hence requiring HIPEC with MMC (Elias et al, 2012; Chua et al, 2012b). Mitomycin C is the drug of choice because of the direct cytotoxicity and the penetrance

\footnotetext{
*Correspondence: Dr EA te Velde; E-mail: e.tevelde@vumc.nl

${ }^{6}$ These two authors contributed equally to this work.

Deceased.
}

Revised 11 November 2014; accepted 7 January 2015; published online 10 February 2015

(C) 2015 Cancer Research UK. All rights reserved 0007 - 0920/15 
of only 1 to $2 \mathrm{~mm}$ (Cerretani et al, 2005; Van Der Speeten et al, 2009). This is thought to cause minimal systemic side effects, while still eliminating minimal residual disease after CRS (Van Ruth et al, 2003). A randomised clinical trial (RCT) in 2003 showed an median overall survival of 22.4 months in patients treated with HIPEC with MMC vs 12.6 months in patients treated with systemic chemotherapy alone (Verwaal et al, 2008). Several other clinical trials followed, revealing a comparable survival gain, with one trial even showing a median overall survival of 62 months (Glehen et al, 2004; Cao et al, 2009; De Cuba et al, 2013). Even when patients are stratified according to the extent of metastasis and residual disease after resection, a subset of patients have decreased survival, giving rise to our hypothesis that these patients might respond differently to MMC (Glehen et al, 2004; Verwaal et al, 2008). If identified, these patients could benefit from an altered approach with optimised tailored treatment with alternative drugs that are readily available and clinically applicable in the HIPEC setting, such as oxaliplatin, irinotecan and doxorubicin (Kusamura et al, 2008; Van Der Speeten et al, 2009; Chua et al, 2012a).

Mitomycin $\mathrm{C}$ functions by intercalating or crosslinking DNA and creating DNA damage, disrupting DNA replication, heralding mitosis and ultimately leading to apoptosis (Szybalski and Iyer, 1964). The cancer cell has several ways of evading and/or repairing MMC-induced damage. One possible way is to inhibit MMC activation as MMC requires enzymatic reduction to become active (Cummings et al, 1998). Several reductases have this capacity, with DT-diaphorase being the most potent and widely researched (Szybalski and Iyer, 1964; Plumb and Workman, 1994; Fitzsimmons et al, 1996; Misra et al, 2002). Absence of this enzyme has been known to lead to increased resistance to MMC in cancer cells (Fitzsimmons et al, 1996). Another way for cancer cells to overcome MMC-induced damage is to repair this damage. This can be facilitated by either the Fanconi anaemia-BRCA (FA-BRCA) pathway or the ATM-ATR pathway that, in turn, both regulate the RAD51C nuclear foci to mediate repair by homologous recombination or nucleotide excision repair
(Figure 1) (D'Andrea and Grompe, 2003; Takemura et al, 2006). Theoretically, if either of these pathways remain intact or even hyperactivated, MMC-related DNA damage could be partially repaired and some degree of resistance can be expected, whereas a nonfunctional pathway may lead to MMC sensitivity as seen in lymphoblasts derived from FA patients (Auerbach, 2009; Oostra et al, 2012). A similar principle has been exposed before in nonsmall-cell lung carcinoma, where the knockout of the FA-BRCA pathway led to a three- to five-fold increase in sensitivity to cisplatin, bearing some resemblance to MMC (Ferrer et al, 2004).

With a mortality ranging from $3 \%$ to $5 \%$ and a morbidity ranging from $15 \%$ to $50 \%$, it is necessary to select patients who will benefit maximally from CRS with HIPEC and exclude patients whose survival gain does not outweigh the treatment-associated morbidity and mortality (Rouers et al, 2006; Cao et al, 2009; Bretcha-Boix et al, 2010; Mizumoto et al, 2012). However, no predictive biomarkers have been found to date that complement the clinical characteristics known to predict outcome (De Cuba et al, 2012). The aim of this study is to characterise biomarkers that predict treatment response to MMC in patients receiving HIPEC for PMs of CRC in order to tailor treatment and subsequently improve survival post CRS and HIPEC.

\section{MATERIALS AND METHODS}

Cell lines and drug sensitivity. Twelve CRC cell lines, HCT116, HCT15, Colo205, Colo320, SW480, SW48, SW1398, CaCo-2, HT-29, LS174T, RKO and LIM1863, were kindly provided by the Tumor Profiling Unit of the Department of Pathology of VU University Medical Center. All cell lines, except LIM1863, were obtained from American Type Culture Collection (LGC Standards $\mathrm{GmbH}$, Wesel, Germany). LIM1863 was kindly provided by Dr RH Whitehead from the Ludwig Institute for Cancer Ltd (Melbourne branch) (Whitehead et al, 1987). The cell lines were routinely

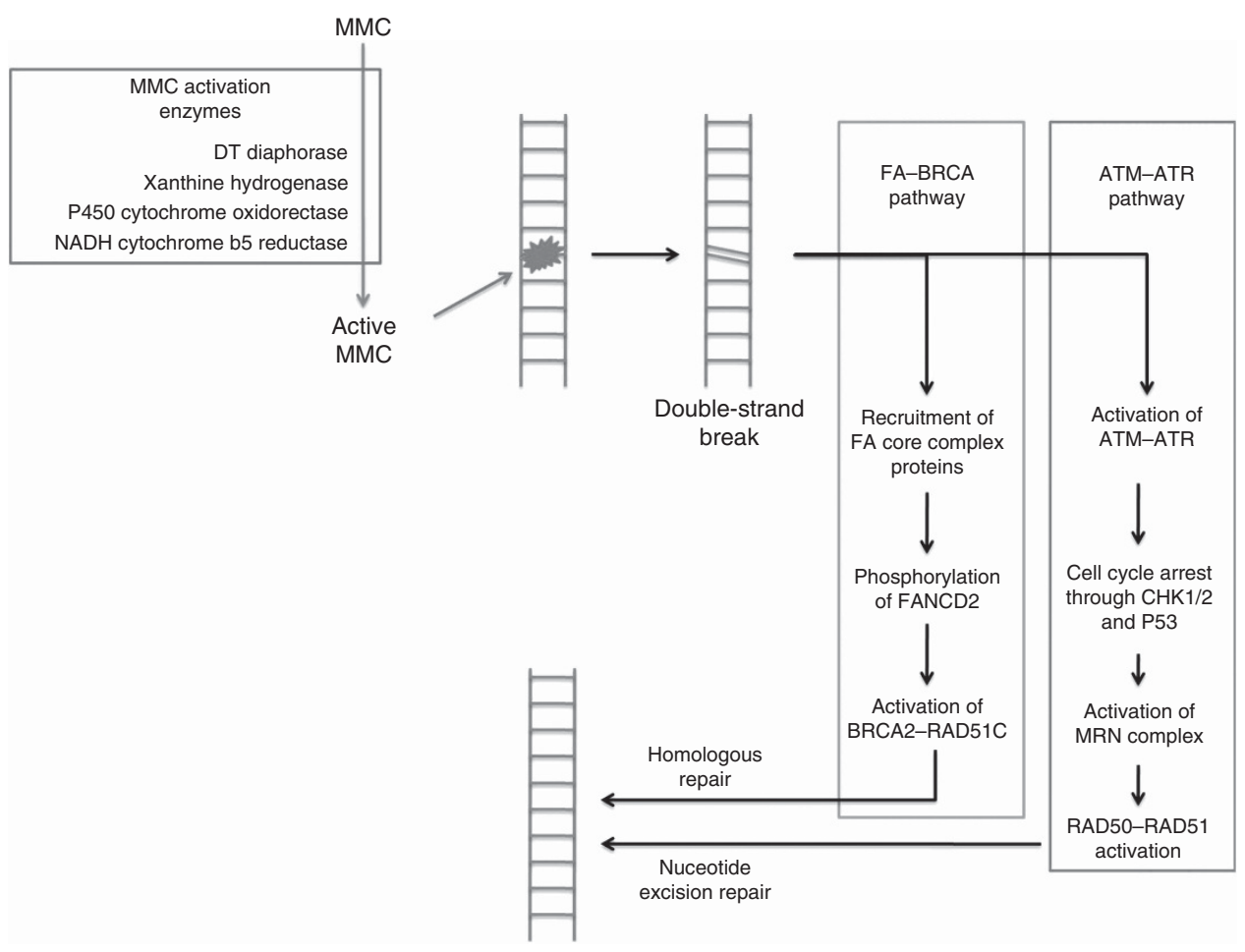

Figure 1. Activation of MMC and repair mechanisms of double-strand breaks. Both the FA-BRCA pathway and the ATM-ATR pathway are illustrated in summary. The FA-BRCA and ATM-ATR pathways have common proteins and intersect on several levels (Cummings et al, 1998; Kitagawa and Kastan, 2005; Chen and Poon, 2008; Kim and D'Andrea, 2012). 
authenticated on the basis of aCGH copy number profile, viability, growth rate and morphology by microscopic examination.

Drug sensitivity of cell lines was determined by the SRB assay (Bijnsdorp et al, 2010). The $\mathrm{IC}_{50}$ values were extracted from the produced graphs. Experiments were conducted in triplicate and the mean of the three experiments is shown.

In order to assess FA-BRCA pathway functionality, negative and positive controls VU1131-T2-8 and VU1131-T2-8 + FANCC cell lines were taken along in the analysis. We categorised cell lines as sensitive, intermediate and resistant in comparison with control cell lines.

Expression array. The RNA was isolated of all 12 CRC cell lines (Ambion Inc., Austin, TX, USA). Synthesis and cDNA labelling were performed according to the manufacturer's recommendations including QC (Agilent Technologies, Palo Alto, CA, USA). Hybridisation was performed on single $44 \mathrm{~K}$ formatted expression arrays containing 41675 60-mer oligonucleotides representing over 27000 well-characterised full-length or partial human genes and expressed sequence tag clusters (G4112A, Agilent Technologies). Scanning was performed using a microarray scanner G2505B (Agilent Technologies) and Feature Extraction v9.5 using the manufacturers protocols (Agilent Technologies). LIMMA-package was used for of background correction, loss within array normalisation and quantile between-array normalisation (Smyth et al, 2005). A total of 37 genes and their mRNA products related to the FA-BRCA pathway, ATM-ATR pathway and/or enzymatic MMC activation were selected based on literature and pathway analysis (Fitzsimmons et al, 1996; Cummings et al, 1998; D’Andrea and Grompe, 2003; Takemura et al, 2006; Chen and Poon, 2008; Kim and D'Andrea, 2012) and subsequently correlated to MMC sensitivity. The data discussed in this publication have been deposited in NCBI's Gene Expression Omnibus and are accessible through GEO Series accession number GSE50494 (http://www.ncbi.nlm.nih.gov/ geo/query/acc.cgi?acc=GSE50494).

FA-BRCA pathway status: chromosomal breakage assay and western blot. The functionality of FA-BRCA pathway was tested with a chromosomal breakage assay (Oostra et al, 2012). Instead of venous blood described in the above-mentioned protocol, trypsinised cell cultures were used. Four slides were prepared per cell line, with MMC addition and without MMC. Metaphases were analysed using MetaphaseFinder (Applied Spectral Imaging Inc, Carlsbad, CA, USA) and scored by an experienced technician.

Fanconi anaemia complementation group D2 protein (FANCD2) was analysed by western blotting in MMC-sensitive cell lines (Ferrer et al, 2004). Western blot was performed using an FANCD2 mouse antibody (F17, Santa Cruz biotechnology Inc., Heidelberg, Germany) diluted at 1:500 in 2\% dry milk in TBST and a peroxidase-conjugated anti-mouse immunoglobulin diluted at 1:5000 in 2\% dry milk in TBST. Cells were treated with hydroxyurea to determine FA pathway activation by monoubiquitination of FANCD2 in response to DNA damage.

Immunohistochemistry. Immunohistochemistry was performed on $4 \mu \mathrm{m}$ slides from FFPE blocks containing embedded CRC cell lines. Slides were stained using the HIER pH6 protocol as described by the manufacturer. Rabbit anti-BLM antibody (Sigma-Aldrich Co. LLC, St Louis, MO, USA), obtained via the Human Protein Atlas (HPA), was utilised in dilution of 1:200 and subsequently incubated for $1 \mathrm{~h}$ at room temperature. This antibody has been validated in previous research (Lao et al, 2013). Secondary antibody PowerVision Poly-HRP anti-Rabbit/Mouse/Rat antibody (Leica Biosystems BV, Nussloch, Germany) was used. Scoring was performed with simple light microscopy and scored by two independent microscopists. As described by HPA, normal liver tissue was used as negative control and placental tissue as positive control.
Patient material. All consecutive patients from a prospectively collected cohort in 2007-2010 undergoing CRS and HIPEC in an expert HIPEC centre (Catharina Hospital, Eindhoven, The Netherlands) with standardised treatment were investigated for Bloom syndrome protein (BLM) expression $(n=33)$. Only patients with histologically confirmed diagnosis of PM of CRC were included. Tumour samples with $<70 \%$ tumour tissue were excluded after staining. Immunohistochemistry was performed with the same protocol as described above. Patient data were subsequently stratified by resection outcome and only R1 outcome, microscopic minimal residual disease (Verwaal et al, 2008), was included in survival analysis $(n=20)$. Median follow-up was 35.3 months with a minimum of 24 months and a maximum of 64 months. Collection, storage and use of tissue and patient data were performed in accordance with the Code for Proper Secondary Use of Human Tissue in the Netherlands.

Statistical analysis. SPSS (version 17; IBM Corporation, Armonk, NY, USA) was used to analyse results. We used linear regression to find a correlation between expression data and clustered sensitivity data. Correlation between clustered sensitivity and immunohistochemistry was assessed using the $\chi^{2}$ test. Patient survival was analysed according to the Kaplan-Meier method. For all mentioned tests, a $P$-value of $<0.05$ was considered significant.

\section{RESULTS}

MMC sensitivity. The $\mathrm{IC}_{50}$ for each cell line was clustered into sensitive (0-50 nM; $n=1)$, intermediate (50-200 nM; $n=7)$ and resistant ( $>200 \mathrm{~nm} ; n=4$ ). Doubling time and MSS/MSI status did not correlate to sensitivity.

mRNA expression. The mRNA expression of 37 genes related to the FA-BRCA, ATM-ATR and MMC activation pathways were analysed for a correlation with clustered sensitivity (Supplementary Table 1). BLM demonstrated a significant correlation with sensitivity at mRNA level $(P=0.01)$ as well as BRCA2 $(P=0.02)$. Both $B L M$ and BRCA2 were observed to be upregulated in the resistant cell lines (Figure 2). The expression of FANCD2, as key protein in the FA-BRCA pathway, displayed no significant correlation with clustered sensitivity. None of the genes of the ATM-ATR pathway or any of the activation enzymes exhibited any correlation to clustered MMC sensitivity (see Supplementary Data). Combined expression levels of BLM and BRCA2 demonstrated no better correlation $(P=0.01)$ than $B L M$ alone. Multivariate analysis was not possible because of limited sample size.

FA-BRCA functionality. Representative cell lines of each sensitivity cluster (sensitive: SW48; intermediate: SW1398 and LS174T; resistant: HCT15) were selected for chromosomal breakage assay. Over $90 \%$ of positive control cells (VU1131-T2-8) displayed $>10$

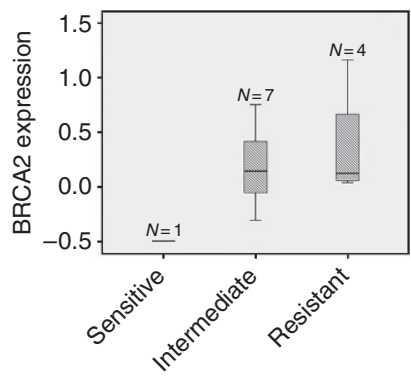

Sensitivity to MMC

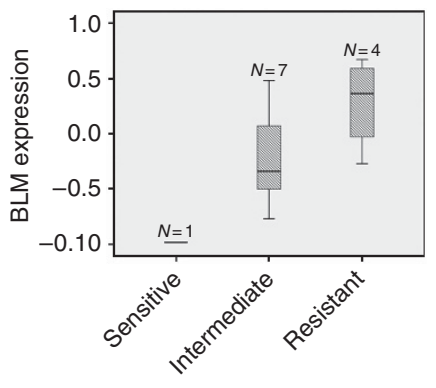

Sensitivity to MMC
Figure 2. The BLM and BRCA2 expression correlated to sensitivity to MMC. Resistant cell lines show higher levels of $B L M$ expression $(P=0.01)$ and higher levels of BRCA2 expression $(P=0.02)$. 
breaks per cell, consistent with a nonfunctional FA-BRCA pathway. Over $80 \%$ of negative control cells (VU1131-T2-8+ FANCC) showed less than three breaks per cells. SW48, HCT15 and LS174T were comparable with the negative control (over $80 \%$ of cells with less than three breaks) (Supplementary Figure 1A). SW1398 exhibited slightly more breaks, yet demonstrated in over $80 \%$ of the cells less than five breaks and was considered negative for chromosomal breakage.

Sensitive cell line SW48 expressed a FANCD2 band on western blot, indicating the presence of the FANCD2 protein, as well as a darker second band with slower mobility after $24 \mathrm{~h}$ of hydroxyurea treatment, illustrating that FANCD2 could be monoubiquitinated and thus be activated (Supplementary Figure 1B).

Immunohistochemistry on BLM. Immunohistochemical staining revealed nuclear and less intense cytoplasmatic staining with significant intratumour heterogeneity, in concordance with previous studies (Suzuki et al, 2001). Considering the nuclear propensity of active BLM and the most active part of the tumour dictating the ultimate response, the strongest nuclear component of staining was scored and used for analysis. Intensity was scored as negative, weak, moderate or strong (Figure 3). Interobserver variability was $<5 \%$. We observed no correlation between mRNA and staining intensity. Correlation between clustered sensitivity and separate staining intensity was not significant $(P=0.17)$. However, negative and weak intensity $v s$ moderate and strong intensity was significantly associated with high $v s$ low sensitivity $(P=0.04)$.

In patient material, 20 out of 33 patient samples were selected by R1 resection outcome. Six patient samples were scored with low intensity (negative plus weak) and 14 patient samples with high intensity (moderate plus strong) for BLM protein (Figure 4). Median
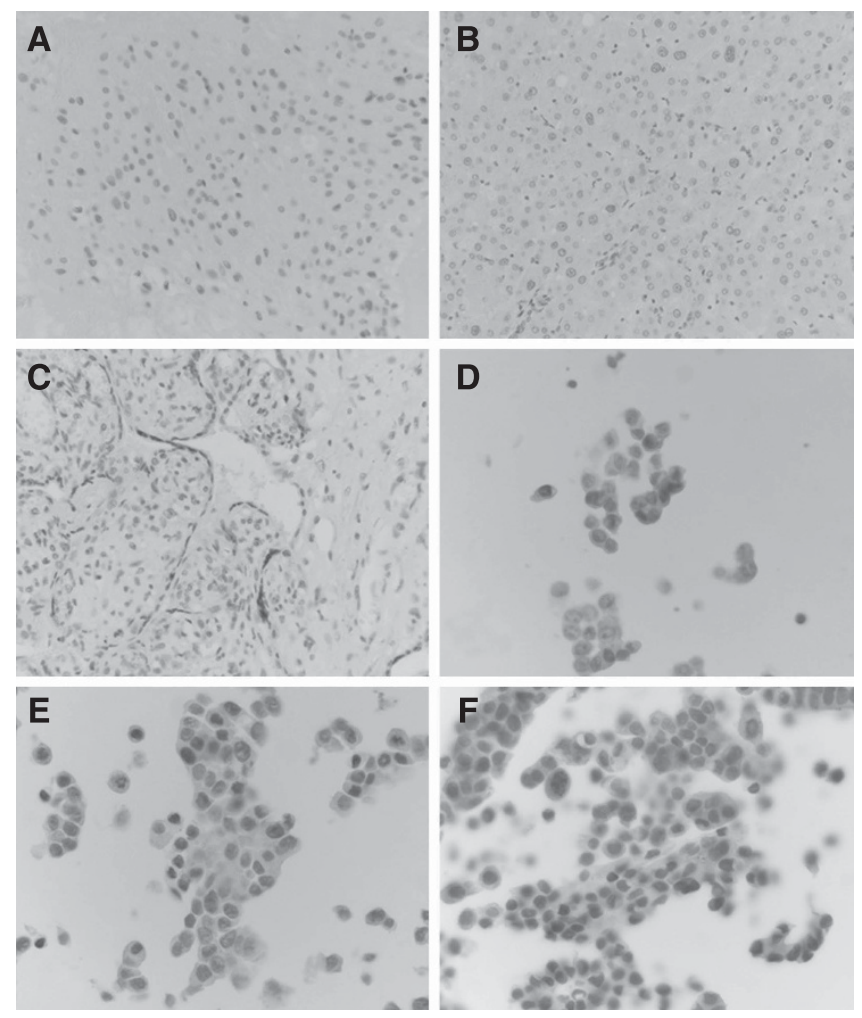

Figure 3. Immunohistochemistry on BLM. (A-C) Blank, negative (liver) and positive (placenta) controls respectively at $\times 10$ objective magnification. (D) SW48 with weak staining $(\times 20$ objective magnification). (E) HT29 with moderate staining ( $\times 20$ objective magnification). (F) Strong staining on Colo205 ( $\times 20$ objective magnification). survival for R1 patients was 23 months (95\% CI: 11.5-34.5). A significant longer survival was found in favour of low BLM expression (high: 15 months (11.3-18.7) vs low: NR; $P=0.04$; Figure 5).

\section{DISCUSSION}

In this study, we demonstrate an association of low BLM with a high sensitivity to MMC and an improved survival. Considering BLM is linked to the FA-BRCA pathway, which is known to play a role in MMC sensitivity, this association seems not unexpected.

In order to select a potential biomarker, we investigated expression levels of 37 different genes involved in the FA-BRCA, ATM-ATR and MMC activation pathways, together responsible for both the activation of $\mathrm{MMC}$ and repairing $\mathrm{MMC}$-induced damage, in association to the MMC sensitivity in 12 CRC cell lines. A significantly higher mRNA expression of both BRCA2 and BLM were found in cell lines resistant to MMC. We found that sensitivity to MMC not only associates to BLM on mRNA level, but also to BLM on protein level. Immunohistochemical analysis of BLM protein correlated to MMC sensitivity in our 12 CRC cell lines. Furthermore, in a prospectively collected cohort of patients with minimal residual disease after CRS, treated with HIPEC using MMC, BLM protein expression was associated with a decreased overall survival.

We linked MMC sensitivity to $B L M$ and BRCA2, strongly suggesting a role for the FA-BRCA pathway in the development of chemoresistance in $\mathrm{CRC}$, yet the chromosomal breakage assay demonstrated no dysfunction of the FA-BRCA pathway in CRC cell lines of any MMC sensitivity level. Concordantly, we observed no association to FANCD2 mRNA or protein expression. This leads to the conclusion that although BLM correlates with MMC sensitivity, this seems to have no implications for the function of DNA repair of the FA-BRCA pathway. It appears that the FA-BRCA pathway can function with either decreased expression levels or is of only limited importance in the development of resistance to MMC in CRC. Hypothetically, the FA-BRCA pathway itself may not be involved in the mechanism dictating response to MMC, but the molecules involved could rather represent surrogate markers for another, still unidentified, pathway that interacts with both BRCA2 and BLM. Perhaps the increased genomic instability as mediated by low levels of BRCA2 and BLM leads to increased sensitivity to DNA crosslinking agents such as MMC. The discrepancies between mRNA and IHC that we found in two cell lines could be because of post-translational modifications. This complex process, consisting of several interacting proteins, is known to mediate protein expression and often relays mRNA expression in different levels of protein expression (Gomes et al, 2014).

Sensitivity to MMC is known to be correlated to DT-diaphorase, encoded by the NQO1 gene (Fitzsimmons et al, 1996; Sharp et al, 2000; Misra et al, 2002), yet the DT-diaphorase overexpressing cell line HT-29 is only intermediately sensitive in our cohort and none of the mRNA products of the MMC activation pathway were significantly correlated to MMC sensitivity. Activation of MMC by DT-diaphorase might be of inferior importance in sensitivity in CRC cell lines, perhaps because of the abundance of other MMCactivating enzymes in human cells that readily transform MMC to its active metabolite (Cummings et al, 1998; Phillips et al, 2000).

The BLM itself is a RecQ helicase that is primarily responsible for unwinding DNA and is known to participate in the BASC complex with BRCA1, the MRN complex (containing RAD50, MRE11 and NBS1) and interact directly with FANCD2 (Ellis et al, 1995; Karow et al, 1997; Wang et al, 2000; Nimonkar et al, 2011). On a cellular level, BLM is involved in stalled replication fork repair, homologous repair, non-homologous end joining and nucleotide excision repair (Bischof et al, 2001; Sengupta et al, 2003; Davalos et al, 2004; Pichierri et al, 2004). In contrast to several 


\begin{tabular}{l} 
Low \\
\hline Negative
\end{tabular}

Figure 4. Immunohistochemistry on patient material for BLM. From left to right: negative, weak, moderate and strong intensity staining $(\times 20$ objective magnification). Negative and weak were clustered for analysis into 'low' as well as moderate and strong into 'high'. Low vs high was significantly correlated to survival $(P=0.04)$.

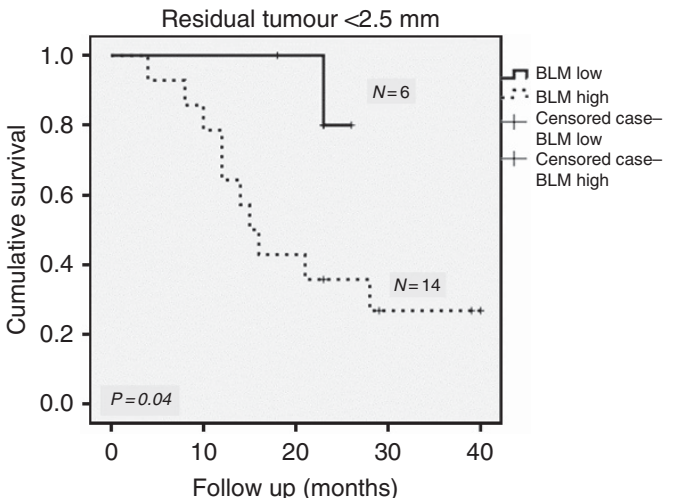

Figure 5. Kaplan-Meier curve of patients with a R1 resection outcome. Patients with a low BLM protein expression demonstrate significant better survival than patients with a high BLM protein expression $(P=0.04)$.

other DNA repair genes, that is $B R C A 2$, the clinical implications of altered BLM expression have not been as well established in cancer (Zhang et al, 2009; Colavito et al, 2010; Liu et al, 2012; Sitzmann and Wiebke, 2013). Even though clinical data are scarce, an important characteristic of BLM is its required activation for repair of DNA double-strand breaks, inducible by intercalating agents such as MMC (Langland et al, 2002). Accordingly, a knockdown of BLM in cell lines sensitises these cells to cisplatin and camptothecin, indicating again the importance of BLM in chemotherapeutic response and its possible clinical relevance (Mao et al, 2010).

In order to further characterise the role of BLM, RNA knockdown experiments in association with investigation of DNA repair proteins could be the next step. Another approach includes proteomics specifically targeting low-abundance nuclear proteins in order to determine the role of BLM in the development of resistance to crosslinking agents such as MMC in CRC cell lines. The results generated by proteomics should then subsequently be validated in a well-defined CRS and HIPEC cohort from an expert HIPEC centre. The ultimate clinical goal is to be able to differentiate between responders and nonresponders to MMC. Nonresponders could then be treated with an alternative intraperitoneal compound.

We conclude that MMC sensitivity in CRC is associated with BLM expression. We are the first to have found a possible predictive biomarker for PMs of CRC and suggest further validation of BLM as a biomarker for treatment stratification before CRS and HIPEC.

\section{ACKNOWLEDGEMENTS}

We thank Kees Smid, Ietje Kathmann, Asma Esidahi and Anneke Oostra for their excellent technical support. In addition, we thank
Meike de Wit and George Scheffer for their expert advice and critical appraisal of the immunohistochemical data. Furthermore, we would sincerely like to thank Dr Victor Verwaal (Netherlands Cancer Institute Antoni van Leeuwenhoek Hospital) for his essential guidance and advice in the implementation of the CRS and HIPEC technique in our institute (2010) and thus enabling us to study this population of metastatic colorectal cancer patients.

\section{CONFLICT OF INTEREST}

The authors declare no conflict of interest.

\section{REFERENCES}

Auerbach AD (2009) Fanconi anemia and its diagnosis. Mutat Res 668: 4-10.

Bijnsdorp IV, Kruyt FA, Fukushima M, Smid K, Gokoel S, Peters GJ (2010) Molecular mechanism underlying the synergistic interaction between trifluorothymidine and the epidermal growth factor receptor inhibitor erlotinib in human colorectal cancer cell lines. Cancer Sci 101: 440-447.

Bischof O, Kim SH, Irving J, Beresten S, Ellis NA, Campisi J (2001) Regulation and localization of the Bloom syndrome protein in response to DNA damage. J Cell Biol 153: 367-380.

Bretcha-Boix P, Farre-Alegre J, Sureda M, Dussan C, Perez Ruixo JJ, Brugarolas Masllorens A (2010) Cytoreductive surgery and perioperative intraperitoneal chemotherapy in patients with peritoneal carcinomatosis of colonic origin: outcomes after 7 years' experience of a new centre for peritoneal surface malignancies. Clin Transl Oncol 12: 437-442.

Cao C, Yan TD, Black D, Morris DL (2009) A systematic review and metaanalysis of cytoreductive surgery with perioperative intraperitoneal chemotherapy for peritoneal carcinomatosis of colorectal origin. Ann Surg Oncol 16: 2152-2165.

Cerretani D, Nencini C, Urso R, Giorgi G, Marrelli D, De Stefano A, Pinto E, Cioppa T, Nastri G, Roviello F (2005) Pharmacokinetics of mitomycin C after resection of peritoneal carcinomatosis and intraperitoneal chemohyperthermic perfusion. J Chemother 17: 668-673.

Chen Y, Poon RY (2008) The multiple checkpoint functions of CHK1 and CHK2 in maintenance of genome stability. Front Biosci 13: 5016-5029.

Chua TC, Esquivel J, Pelz JO, Morris DL (2012a) Summary of current therapeutic options for peritoneal metastases from colorectal cancer. J Surg Oncol 107(6): 566-573.

Chua TC, Pelz JO, Morris DL (2012b) Surgery for colorectal peritoneal carcinomatosis. Scand J Gastroenterol 47: 277-285.

Colavito S, Prakash R, Sung P (2010) Promotion and regulation of homologous recombination by DNA helicases. Methods 51: 329-335.

Cummings J, Spanswick VJ, Tomasz M, Smyth JF (1998) Enzymology of mitomycin $\mathrm{C}$ metabolic activation in tumour tissue: implications for enzyme-directed bioreductive drug development. Biochem Pharmacol 56: 405-414.

D'Andrea AD, Grompe M (2003) The Fanconi anaemia/BRCA pathway. Nat Rev Cancer 3: 23-34.

Davalos AR, Kaminker P, Hansen RK, Campisi J (2004) ATR and ATMdependent movement of BLM helicase during replication stress ensures 
optimal ATM activation and 53BP1 focus formation. Cell Cycle 3: $1579-1586$

De Cuba EM, Kwakman R, Knol DL, Bonjer HJ, Meijer GA, Te Velde EA (2013) Cytoreductive surgery and HIPEC for peritoneal metastases combined with curative treatment of colorectal liver metastases: systematic review of all literature and meta-analysis of observational studies. Cancer Treat Rev 39: 321-327.

De Cuba EM, Kwakman R, Van Egmond M, Bosch LJ, Bonjer HJ, Meijer GA, Te Velde EA (2012) Understanding molecular mechanisms in peritoneal dissemination of colorectal cancer: future possibilities for personalised treatment by use of biomarkers. Virchows Arch 461(3): 231-243.

Elias D, Quenet F, Goere D (2012) Current status and future directions in the treatment of peritoneal dissemination from colorectal carcinoma. Surg Oncol Clin N Am 21: 611-623.

Ellis NA, Groden J, Ye TZ, Straughen J, Lennon DJ, Ciocci S, Proytcheva M, German J (1995) The Bloom's syndrome gene product is homologous to RecQ helicases. Cell 83: 655-666.

Ferrer M, De Winter JP, Mastenbroek DC, Curiel DT, Gerritsen WR, Giaccone G, Kruyt FA (2004) Chemosensitizing tumor cells by targeting the Fanconi anemia pathway with an adenovirus overexpressing dominant-negative FANCA. Cancer Gene Ther 11: 539-546.

Fitzsimmons SA, Workman P, Grever M, Paull K, Camalier R, Lewis AD (1996) Reductase enzyme expression across the National Cancer Institute Tumor cell line panel: correlation with sensitivity to mitomycin $\mathrm{C}$ and EO9. J Natl Cancer Inst 88: 259-269.

Glehen O, Kwiatkowski F, Sugarbaker PH, Elias D, Levine EA, De Simone M, Barone R, Yonemura Y, Cavaliere F, Quenet F, Gutman M, Tentes AA, Lorimier G, Bernard JL, Bereder JM, Porcheron J, Gomez-Portilla A, Shen P, Deraco M, Rat P (2004) Cytoreductive surgery combined with perioperative intraperitoneal chemotherapy for the management of peritoneal carcinomatosis from colorectal cancer: a multi-institutional study. J Clin Oncol 22: 3284-3292.

Gomes IM, Santos CR, Maia CJ (2014) Expression of STEAP1 and STEAP1B in prostate cell lines, and the putative regulation of STEAP1 by posttranscriptional and post-translational mechanisms. Genes Cancer 5: 142-151.

Karow JK, Chakraverty RK, Hickson ID (1997) The Bloom's syndrome gene product is a $3^{\prime}-5^{\prime}$ DNA helicase. J Biol Chem 272: 30611-30614.

Kim H, D'Andrea AD (2012) Regulation of DNA cross-link repair by the Fanconi anemia/BRCA pathway. Genes Dev 26: 1393-1408.

Kitagawa R, Kastan MB (2005) The ATM-dependent DNA damage signaling pathway. Cold Spring Harb Symp Quant Biol 70: 99-109.

Kusamura S, Dominique E, Baratti D, Younan R, Deraco M (2008) Drugs, carrier solutions and temperature in hyperthermic intraperitoneal chemotherapy. J Surg Oncol 98: 247-252.

Langland G, Elliott J, Li Y, Creaney J, Dixon K, Groden J (2002) The BLM helicase is necessary for normal DNA double-strand break repair. Cancer Res 62: 2766-2770.

Lao VV, Welcsh P, Luo Y, Carter KT, Dzieciatkowski S, Dintzis S, Meza J, Sarvetnick NE, Monnat Jr. RJ, Loeb LA, Grady WM (2013) Altered RECQ helicase expression in sporadic primary colorectal cancers. Transl Oncol 6: 458-469.

Liu G, Yang D, Sun Y, Shmulevich I, Xue F, Sood AK, Zhang W (2012) Differing clinical impact of BRCA1 and BRCA2 mutations in serous ovarian cancer. Pharmacogenomics 13: 1523-1535.

Mao FJ, Sidorova JM, Lauper JM, Emond MJ, Monnat RJ (2010) The human WRN and BLM RecQ helicases differentially regulate cell proliferation and survival after chemotherapeutic DNA damage. Cancer Res 70: 6548-6555.

Misra V, Klamut HJ, Rauth AM (2002) Expression of the prodrug-activating enzyme DT-diaphorase via Ad5 delivery to human colon carcinoma cells in vitro. Cancer Gene Ther 9: 209-217.

Mizumoto A, Canbay E, Hirano M, Takao N, Matsuda T, Ichinose M, Yonemura Y (2012) Morbidity and mortality outcomes of cytoreductive surgery and hyperthermic intraperitoneal chemotherapy at a single institution in Japan. Gastroenterol Res Pract 2012: 836425.

Nimonkar AV, Genschel J, Kinoshita E, Polaczek P, Campbell JL, Wyman C, Modrich P, Kowalczykowski SC (2011) BLM-DNA2-RPA-MRN and EXO1-BLM-RPA-MRN constitute two DNA end resection machineries for human DNA break repair. Genes Dev 25: 350-362.
Oostra AB, Nieuwint AW, Joenje H, De Winter JP (2012) Diagnosis of fanconi anemia: chromosomal breakage analysis. Anemia 2012: 238731.

Phillips RM, Burger AM, Loadman PM, Jarrett CM, Swaine DJ, Fiebig HH (2000) Predicting tumor responses to mitomycin C on the basis of DT-diaphorase activity or drug metabolism by tumor homogenates: implications for enzyme-directed bioreductive drug development. Cancer Res 60: 6384-6390.

Pichierri P, Franchitto A, Rosselli F (2004) BLM and the FANC proteins collaborate in a common pathway in response to stalled replication forks. EMBO J 23: 3154-3163.

Plumb JA, Workman P (1994) Unusually marked hypoxic sensitization to indoloquinone $\mathrm{EO} 9$ and mitomycin $\mathrm{C}$ in a human colon-tumour cell line that lacks DT-diaphorase activity. Int J Cancer 56: 134-139.

Rouers A, Laurent S, Detroz B, Meurisse M (2006) Cytoreductive surgery and hyperthermic intraperitoneal chemotherapy for colorectal peritoneal carcinomatosis: higher complication rate for oxaliplatin compared to mitomycin C. Acta Chir Belg 106: 302-306.

Sengupta S, Linke SP, Pedeux R, Yang Q, Farnsworth J, Garfield SH, Valerie K, Shay JW, Ellis NA, Wasylyk B, Harris CC (2003) BLM helicasedependent transport of p53 to sites of stalled DNA replication forks modulates homologous recombination. EMBO J 22: 1210-1222.

Sharp SY, Kelland LR, Valenti MR, Brunton LA, Hobbs S, Workman P (2000) Establishment of an isogenic human colon tumor model for NQO1 gene expression: application to investigate the role of DT-diaphorase in bioreductive drug activation in vitro and in vivo. Mol Pharmacol 58: 1146-1155.

Sitzmann JV, Wiebke EA (2013) Risk-reducing appendectomy and the elimination of BRCA1-associated intraperitoneal cancer. JAMA Surg 148: 285-291, discussion 291.

Smyth GK, Michaud J, Scott HS (2005) Use of within-array replicate spots for assessing differential expression in microarray experiments. Bioinformatics 21: 2067-2075.

Suzuki H, Seki M, Kobayashi T, Kawabe Y, Kaneko H, Kondo N, Harata M, Mizuno S, Masuko T, Enomoto T (2001) The N-terminal internal region of BLM is required for the formation of dots/rod-like structures which are associated with SUMO-1. Biochem Biophys Res Commun 286: 322-327.

Szybalski W, Iyer VN (1964) Crosslinking of DNA by enzymatically or chemically activated mitomycins and porfiromycins, bifunctionally "alkylating" antibiotics. Fed Proc 23: 946-957.

Takemura H, Rao VA, Sordet O, Furuta T, Miao ZH, Meng L, Zhang H, Pommier Y (2006) Defective Mre11-dependent activation of Chk2 by ataxia telangiectasia mutated in colorectal carcinoma cells in response to replication-dependent DNA double strand breaks. J Biol Chem 281: 30814-30823.

Van Der Speeten K, Stuart OA, Sugarbaker PH (2009) Pharmacokinetics and pharmacodynamics of perioperative cancer chemotherapy in peritoneal surface malignancy. Cancer J 15: 216-224.

Van Ruth S, Verwaal VJ, Zoetmulder FA (2003) Pharmacokinetics of intraperitoneal mitomycin C. Surg Oncol Clin N Am 12: 771-780.

Verwaal VJ, Bruin S, Boot H, Van Slooten G, Van Tinteren H (2008) 8-year follow-up of randomized trial: cytoreduction and hyperthermic intraperitoneal chemotherapy versus systemic chemotherapy in patients with peritoneal carcinomatosis of colorectal cancer. Ann Surg Oncol 15: 2426-2432.

Wang Y, Cortez D, Yazdi P, Neff N, Elledge SJ, Qin J (2000) BASC, a super complex of BRCA1-associated proteins involved in the recognition and repair of aberrant DNA structures. Genes Dev 14: 927-939.

Whitehead RH, Jones JK, Gabriel A, Lukies RE (1987) A new colon carcinoma cell line (LIM1863) that grows as organoids with spontaneous differentiation into crypt-like structures in vitro. Cancer Res 47: 2683-2689.

Zhang F, Ma J, Wu J, Ye L, Cai H, Xia B, Yu X (2009) PALB2 links BRCA1 and BRCA2 in the DNA-damage response. Curr Biol 19: 524-529.

This work is published under the standard license to publish agreement. After 12 months the work will become freely available and the license terms will switch to a Creative Commons AttributionNonCommercial-Share Alike 4.0 Unported License.

Supplementary Information accompanies this paper on British Journal of Cancer website (http://www.nature.com/bjc) 